Article

\title{
Preparation and Thermomechanical Properties of Ketone Mesogenic Liquid Crystalline Epoxy Resin Composites with Functionalized Boron Nitride
}

\author{
Yi-Sheng Lin ${ }^{1,2}$, Steve Lien-Chung Hsu ${ }^{1, * \mathbb{C}}$, Tsung-Han Ho ${ }^{3}$, Li-Cheng Jheng ${ }^{3} \mathbb{C}$ and \\ Yu-Hsiang Hsiao ${ }^{2}$ \\ 1 Department of Materials Science \& Engineering, National Cheng Kung University, Tainan 701-01, Taiwan; \\ sheng-013@hotmail.com \\ 2 Product Characterization, Advanced Semiconductor Engineering, Inc., Kaohsiung 801-70, Taiwan; \\ Hunter_Hsiao@aseglobal.com \\ 3 Department of Chemical \& Materials Engineering, National Kaohsiung University of Science and \\ Technology, Kaohsiung 807-78, Taiwan; thho@nkust.edu.tw (T.-H.H.); lcjheng@nkust.edu.tw (L.-C.J.) \\ * Correspondence: lchsu@mail.ncku.edu.tw; Tel.: +886-6-275-7575 (ext. 62904); Fax: +886-6-234-6290
}

Received: 18 July 2020; Accepted: 22 August 2020; Published: 25 August 2020

\begin{abstract}
In order to enhance the thermomechanical behaviors of epoxy molding compounds, the hexagonal boron nitride (h-BN) fillers were incorporated in a ketone mesogenic liquid crystalline epoxy (K-LCE) matrix to prepare a high-performance epoxy composites. The h-BN was modified by surface coupling agent 3-aminopropyltriethoxysilane (APTES). The grafting of silane molecules onto the surface of BN fillers improved the compatibility and homogeneous dispersion state of BN fillers in the K-LCE matrix with a strong interface interaction. The surface-modified BN fillers were characterized using Fourier transform infrared spectroscopy. The thermomechanical properties and morphologies of K-LCE/BN composites loading with different contents of modified BN fillers, ranging from 0.50 to $5.00 \mathrm{wt} \%$, were investigated. These results show that modified BN fillers uniformly dispersed in K-LCE matrix, contributing to the enhancement in storage modulus, glass transition temperatures, impact strength and reduction in the coefficient of thermal expansion (CTE). The thermal stability and char yield of the K-LCE/BN composites were increased by increasing the amount of modified BN fillers and the thermal decomposition temperatures of composites were over $370{ }^{\circ} \mathrm{C}$. The thermal conductivity of the $\mathrm{K}-\mathrm{LCE} / \mathrm{BN}$ composites was up to $0.6 \mathrm{~W} / \mathrm{m} \cdot \mathrm{K}$, for LC epoxy filled with 5.00-wt\%-modified BN fillers. Furthermore, the K-LCE/BN composites have excellent thermal and mechanical properties compared to those of the DGEBA/BN composites.
\end{abstract}

Keywords: liquid crystalline epoxy resin; boron nitride; composites; surface modification; thermomechanical properties

\section{Introduction}

With the development of electronic packaging technology, the heat management is becoming increasingly important, which has led to the increased demand for higher density and higher power integrated circuits (ICs). When high-power-density devices are worked, a large amount of heat is produced. The issue of heat dissipation must be improved to prevent overheating [1-3].

Epoxy molding compounds (EMCs) and underfills has often been used as electrical encapsulating materials for microelectronic devices to provide protection of the IC devices [4]. However, common epoxy resins have poor thermal properties such as high CTE and low thermal conductivity $(0.17-0.20 \mathrm{~W} / \mathrm{m} \cdot \mathrm{K})$, but these properties of epoxides can be improved by the rigid rod structures with liquid crystalline characteristics introduced [5-8]. We have reported that the liquid crystalline (LC) 
epoxy resin exhibited much lower CTE and a higher thermal conductivity $(0.34 \mathrm{~W} / \mathrm{m} \cdot \mathrm{K})$ compared to those of a traditional epoxy resin (DGEBA) [9]. In general, the ICs are encapsulated by silica-filled epoxy composites, but the thermal conductivity of the composites is less than $1.0 \mathrm{~W} / \mathrm{m} \cdot \mathrm{K}$, which is far below the demand of ICs heat dissipation [10]. It can be enhanced by incorporation of inorganic fillers with a high thermal conductivity and electrical insulation, such as alumina $\left(\mathrm{Al}_{2} \mathrm{O}_{3}\right)$ [11-15], silicon carbide ( $\mathrm{SiC}$ ) [16-18], silicon nitride $\left(\mathrm{Si}_{3} \mathrm{~N}_{4}\right)$ [19-21], aluminum nitride (AlN) [22-26], boron nitride (BN) [27-32], carbon nanotubes (CNTs) [33-35] and grapheme [36-38] or other ceramic fillers. Boron nitride with a hexagonal lattice structure (h-BN) is a platelet-shaped ceramic and is often called "white graphite". $\mathrm{h}$-BN has the greatest potential application in polymer composites due to its superior intrinsic thermal conductivity (up to $400 \mathrm{~W} / \mathrm{m} \cdot \mathrm{k}$ ), excellent electrical insulation properties, thermal stability with low dielectric constant and low density, compared to those of $\mathrm{Al}_{2} \mathrm{O}_{3}, \mathrm{SiC}, \mathrm{Si}_{3} \mathrm{~N}_{4}$ and AlN. Therefore, in order to obtain the better thermal and mechanical properties of the composites, it is necessary to increase the interface between filler and epoxy matrix by surface modification with chemical treatment. The surface modification of inorganic filler improves the affinity of the filler matrix, which provides strong interconnection and homogeneous dispersion. Hence, the incorporation of functionalized ceramic materials in polymers enhances the demand of highly thermally properties for electronic encapsulation application.

In this study, a LC epoxy resin containing ketone mesogenic group was synthesized and a silane-coupling agent 3-aminopropyltriethoxysilane was used to modify the surface of h-BN fillers. The h-BN surface treatment was characterized, which confirms the silane functional groups were grafted onto the h-BN surface. The surface modification of BN fillers dispersed in LC epoxy resin matrix and then cured using aromatic amines as curing agent to produce high-performance composites. Its morphology and the dispersion states were examined. The thermomechanical properties, thermal stability and thermal conductivity of the cured composites were also investigated.

\section{Experimental Section}

\subsection{Materials}

Hexagonal boron nitride (h-BN) with an average diameter of $1 \mu \mathrm{m}$ was purchased from Aldrich. 3-aminopropyltriethoxysilane (APTES) was purchased from Acros (Geel, Belgium). 4,4'-diaminodiphenylsulfone (DDS) was purchased from Tokyo Chemical Industry (TCI, Tokyo, Japan). Sulfuric acid, nitric acid and hydrochloric acid were purchased from TEDIA (Fairfield, OH, USA). Ethanol was purchased from ECHO (Lake Zurich, IL, USA). All chemicals and solvents were analytical grade and used directly without further purification as received.

\subsection{Synthesis of 1,5-bis( $\rho$-glycidyloxy-phenyl)-1,4-pentadiene-3-one (K-LCE)}

The K-LCE was synthesized following the method described in our previous work [9]. The synthetic route of K-LCE is shown in Scheme 1. The product as a yellow powder was recrystallized from ethanol.

K-LCE: calcd. 378; found: 379. ${ }^{1} \mathrm{H}$ NMR (acetone- $\left.\mathrm{D}_{6}\right): \delta=2.75,2.90\left(4 \mathrm{H}\right.$, epoxy- $\left.\mathrm{CH}_{2}\right)$, $3.34\left(2 \mathrm{H}\right.$, epoxy-CH), 3.93, $4.27\left(4 \mathrm{H}\right.$, glycidyl- $\left.\mathrm{CH}_{2}\right), 6.92,7.53(8 \mathrm{H}$, aromatic), $7.09(2 \mathrm{H}, \mathrm{Ph}-\mathrm{CH}=)$, $7.69(2 \mathrm{H},=\mathrm{CH}-)$. The epoxy equivalent weight $(\mathrm{EEW})$ was determined using the $\mathrm{HClO}_{4} /$ potentiometric titration method and found to be $196.2 \mathrm{~g} \cdot \mathrm{eq}^{-1}$. 


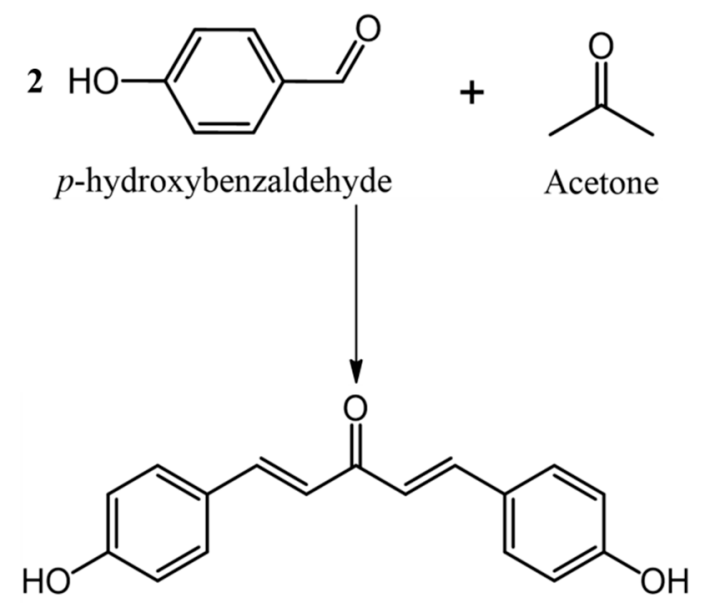

1,5-Bis(4-hydroxyphenyl)-1,4-pentadiene-3-one<smiles>O=C(/C=C/c1ccc(OCC2CO2)cc1)/C=C/c1ccc(OCC2CO2)cc1</smiles>

1,5-Bis(p-glycidyloxy-phenyl)-1,4-pentadiene-3-one

Scheme 1. Synthesis of ketone mesogenic liquid crystalline epoxy (K-LCE).

\subsection{Surface Modification of BN Fillers}

In order to decrease the agglomeration of h-BN fillers, sulfuric acid, nitric acid and silane were used for surface treatment, and the surface of h-BN was functionalized to increase the degree of dispersion in K-LCE. First, $500 \mathrm{mg}$ of BN powder was added into a 400-mL mixture solution of sulfuric acid and nitric acid (volume ration $=3: 1$ ), and the mixture was ultrasonicated for $10 \mathrm{~h}$. The mixture was stirred with reflux condensation at $80^{\circ} \mathrm{C}$ for $72 \mathrm{~h}$ and then cooled to room temperature. The resulting solution was filtered off, washed with deionized water and then dried at $60{ }^{\circ} \mathrm{C}$ under vacuum for $24 \mathrm{~h}$. This pretreatment method was first, carried out to introduce the hydroxyl groups onto the surface of h-BN fillers through strong oxidation, named $\mathrm{OH}-\mathrm{BN}$.

Second, OH-BN fillers were modified with a silane-coupling agent APTES for grafting of hyperbranched. In a 250-mL three-neck flask, the mixture of deionized water and APTES $($ mole ratio $=12: 1)$ were magnetic stirred for $30 \mathrm{~min}$. The hydrolytic solution was added into ethanol and adjusted the $\mathrm{pH}$ to 3 with hydrochloric acid. Then the $5 \mathrm{~g} \mathrm{OH}-\mathrm{BN}$ filler was added into the mixed solution. The resulting mixture was heated to $70{ }^{\circ} \mathrm{C}$ and magnetic stirred for $5 \mathrm{~h}$. After cooling, the silane modified BN filler was filtered, washed with ethanol and then obtained after dried at $60^{\circ} \mathrm{C}$ under vacuum for $24 \mathrm{~h}$, name Si-BN [29].

\subsection{Preparation of $K-L C E / B N$ Composites}

The K-LCE-based composites were prepared as follows: First of all, a stoichiometric ratio of the $\mathrm{K}-\mathrm{LCE}$ and curing agent DDS were mixed and the weight ratio of the $\mathrm{Si}-\mathrm{BN}$ which set at $0.50,1.00$, 2.00 and $5.00 \mathrm{wt} \%$ were added to the mixture and pestle together in an agate mortar, respectively. Second, the mixture powders were poured into die, adequately degassed using manual hydraulic 
press and then placed into an aluminum mold. Finally, the K-LCE/BN composites were obtained after pre-cured at $120^{\circ} \mathrm{C}$ for $1 \mathrm{~h}, 170{ }^{\circ} \mathrm{C}$ for $2 \mathrm{~h}$ and post-cured at $210{ }^{\circ} \mathrm{C}$ for $3 \mathrm{~h}$. Figure 1 illustrates the process of the $\mathrm{K}-\mathrm{LCE} / \mathrm{BN}$ composites fabrication.

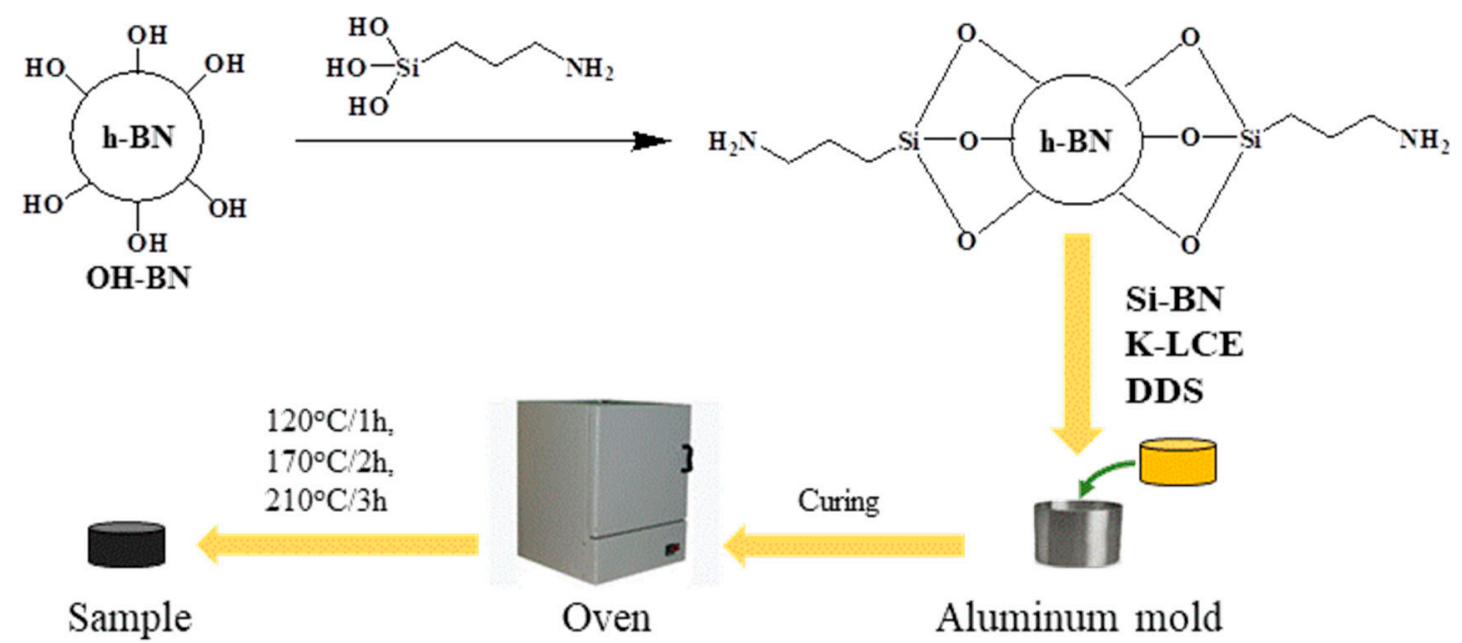

Figure 1. Process of the K-LCE/ boron nitride (BN)composites fabrication.

\subsection{Characterization}

FTIR spectra were recorded on PerkinElmer GX50003 instrument ranging from 4000 to $400 \mathrm{~cm}^{-1}$. The spectra of specimens were obtained by dispersing them in potassium bromide $(\mathrm{KBr})$ and scanning. The surface morphologies of the K-LCE/BN composites were examined by scanning electron microscopy (SEM; Phenom XL, Waltham, MA, USA). The liquid crystalline property of the K-LCE/BN composites was observed by polarized optical microscopy (POM, Olympus BS51, Tokyo, Japan) with a heating stage during the curing process. The storage modulus and glass transition temperature $\left(\mathrm{T}_{\mathrm{g}}\right)$ were measured using a dynamic mechanical thermal analyzer (DMA; DMA Q800, TA Instruments, New Castle, DE, USA) with three-point bending mode at a frequency of $1 \mathrm{~Hz}$. Specimens with dimensions of $20 \mathrm{~mm} \times 15 \mathrm{~mm} \times 2 \mathrm{~mm}$ were measured from the temperature range of 0 to $270{ }^{\circ} \mathrm{C}$ at a heating rate of $5{ }^{\circ} \mathrm{C} / \mathrm{min}$. The in-plane $\mathrm{CTE}$ was determined using a thermal mechanical analyzer (TMA; TMA Q400, TA Instruments, New Castle, DE, USA). The CTEs were tested by the expansion mode under a $0.05-\mathrm{N}$ tension force from the temperature range of 0 to $270{ }^{\circ} \mathrm{C}$ at a heating rate of $5{ }^{\circ} \mathrm{C} / \mathrm{min}$. The impact testing for V-shape notched specimens was performed with a Charpy impact tester according to ASTM D6110. The impact strength was measured at room temperature and the impact velocity was $3.1 \mathrm{~m} / \mathrm{s}$. The decomposition temperature and weight loss were measured using a thermogravimetric analyzer (TGA; TGA Q500, TA Instruments, New Castle, USA) from room temperature to $800^{\circ} \mathrm{C}$ at a heating rate of $10^{\circ} \mathrm{C} / \mathrm{min}$ under nitrogen gas. The thermal conductivities of the composite at room temperature were determined using a hot disk thermal conductivity analyzer (TPS2500, Gothenburg, Sweden) equipped with a Kapton disk-shaped sensor.

\section{Results and Discussion}

\subsection{Characterization of BN Surface Modification}

FTIR was performed to validate the grafting of the silane-coupling agent APTES on the h-BN surface during acid treatment and silanization. The FTIR spectra of the acid-treated OH-BN (a), APTES (b) and the silane-modified Si-BN (c) are shown in Figure 2 for comparison. The broad absorption peaks of OH-BN and APTES showed at around $3430 \mathrm{~cm}^{-1}$, which corresponded to the hydroxyl groups and amino groups, respectively. The strong absorption peaks at 1398 and $780 \mathrm{~cm}^{-1}$ are attributed to the vibration of $\mathrm{B}-\mathrm{N}$ in-plane stretching and $\mathrm{B}-\mathrm{N}-\mathrm{B}$ out-of-plane bending, respectively. After $\mathrm{OH}-\mathrm{BN}$ modified with silane, the new peaks at 3013, 2824, 1140 and $1036 \mathrm{~cm}^{-1}$ appeared in 
the IR spectrum of $\mathrm{Si}-\mathrm{BN}$, which corresponded to symmetric and asymmetric stretching vibrations of the methylene group of APTES and O-Si-O stretching, respectively. From the chemical structure characterization results that the silane-coupling agent APTES is successfully grafted on the h-BN surface.

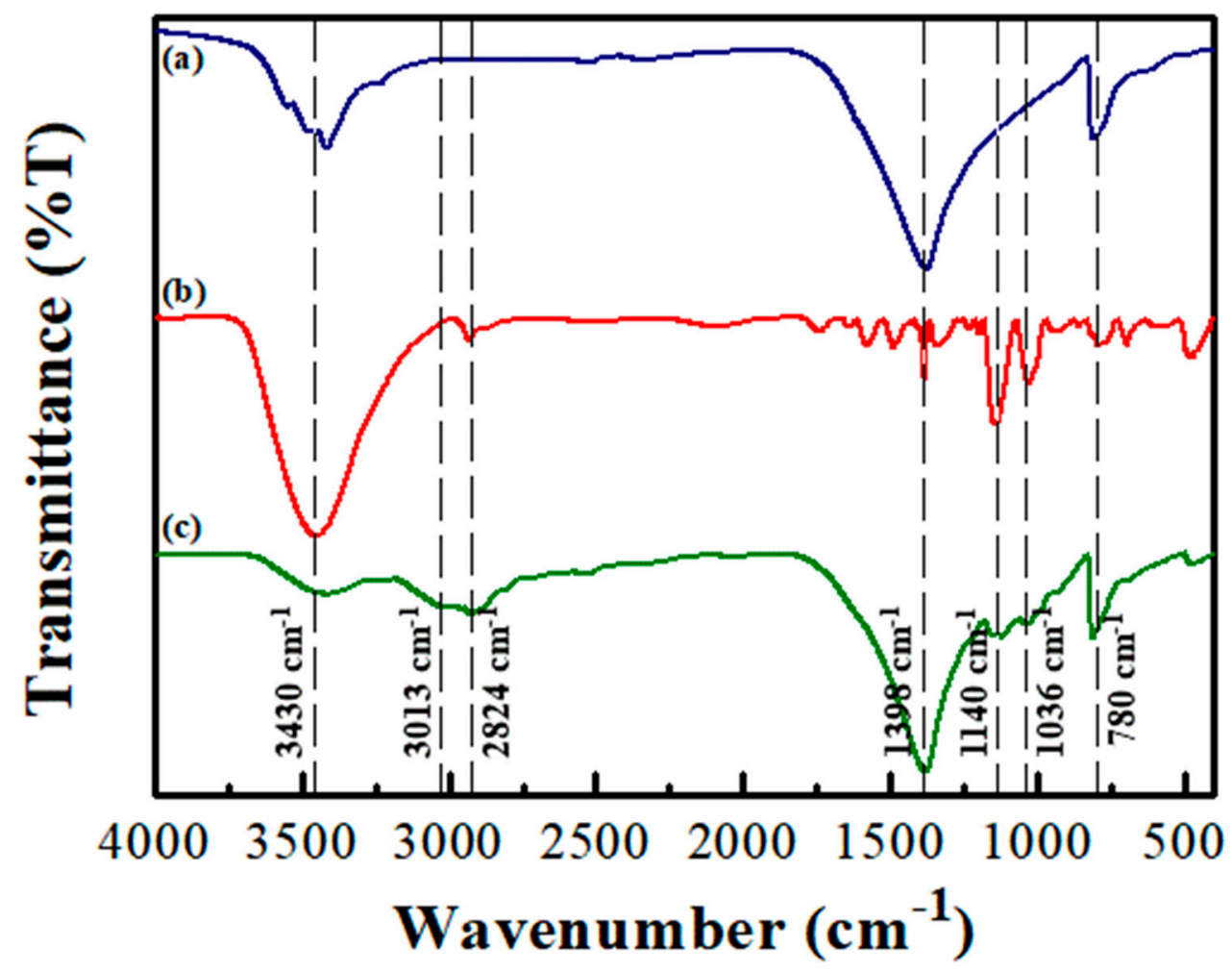

Figure 2. FTIR spectra. (a) Acid-treated OH-BN; (b) APTES; (c) silane-modified Si-BN.

\subsection{Morphology Observation of K-LCE/BN Composites}

The morphology of K-LCE/BN composites and the dispersion states of h-BN fillers in the K-LCE matrix were examined. Representative SEM images of the fractured surfaces of the K-LCE and K-LCE with different h-BN filler contents are shown in Figure 3. The neat K-LCE shows a smooth fractured surface in Figure 3a. The fractured shape of crack propagation reveals as river patterns, which indicated a brittle structure. For the composites with $2.00 \mathrm{wt} \%$ filer content, Figure $3 \mathrm{~d}$ shows that h-BN fillers were well dispersed uniformly in the K-LCE matrix compared to those of the composites with 0.50 and $1.00 \mathrm{wt} \%$ filler content, as shown in Figure 3b,c. The surface morphologies of the Si-BN and raw h-BN-based composites with $5.00 \mathrm{wt} \%$ filler content are shown in Figure 3e,f, respectively. By comparisons, the raw h-BN-based composites showed much voids and the agglomeration of fillers. On the other hand, the surface-modified BN revealed good homogeneity and dispersion in K-LCE matrix without voids and agglomeration. This is due to the bonding between silane-coupling agent and the h-BN surface is to decrease the interaction of filler-filler and to enhance interfacial properties of the surface-modified BN fillers in the K-LCE matrix, such as good compatibility and uniform dispersion [27]. In addition, all the composites showed a rough fractured surface because of the K-LCE matrix shear yielding, which resulted by h-BN fillers added. 

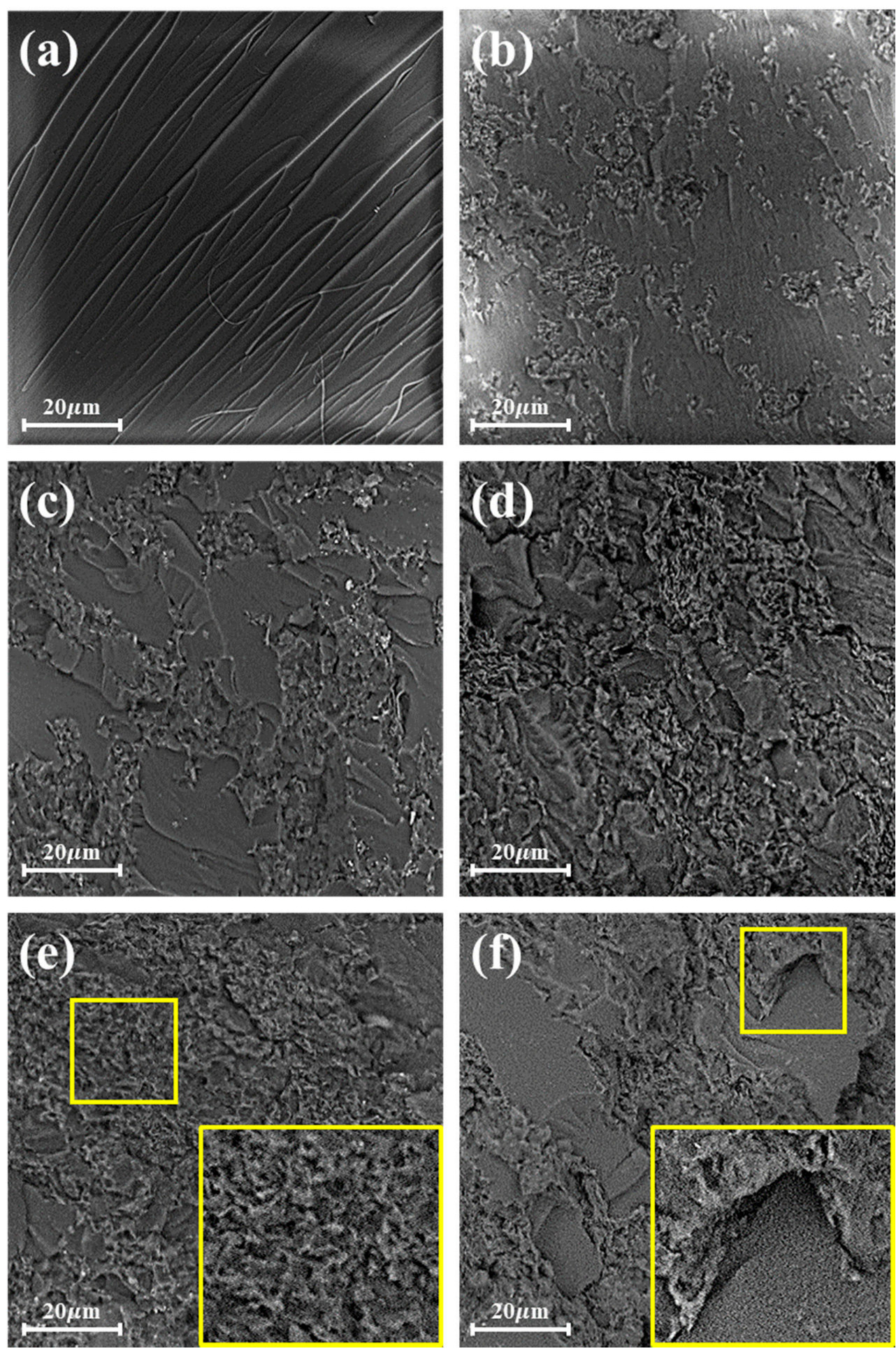

Figure 3. SEM images. (a)Fractured surface of neat K-LCE; (b) fractured surface of $0.50 \mathrm{wt} \%$ $\mathrm{Si}-\mathrm{BN} / \mathrm{K}-\mathrm{LCE}$ composites; (c) fractured surface of $1.00 \mathrm{wt} \% \mathrm{Si}-\mathrm{BN} / \mathrm{K}-\mathrm{LCE}$ composites; (d) fractured surface of $2.00 \mathrm{wt} \% \mathrm{Si}-\mathrm{BN} / \mathrm{K}-\mathrm{LCE}$ composites; (e) fractured surface of $5.00 \mathrm{wt} \% \mathrm{Si}-\mathrm{BN} / \mathrm{K}-\mathrm{LCE}$ composites; (f) fractured surface of $5.00 \mathrm{wt} \%$ raw $\mathrm{BN} / \mathrm{K}-\mathrm{LCE}$ composites.

To further examine the texture formation during the curing process, the liquid crystalline phase of K-LCE/BN/DDS mixtures was observed using POM with a heating stage at the isothermal curing temperature. Figure 4 shows the POM image of cured K-LCE/BN composites. The cured K-LCE/BN composites showed the smectic phase which can also offer excellent physical properties. This is 
due to the mesogenic characteristic of liquid crystalline being introduced to produce a high orderly arrangement networks.

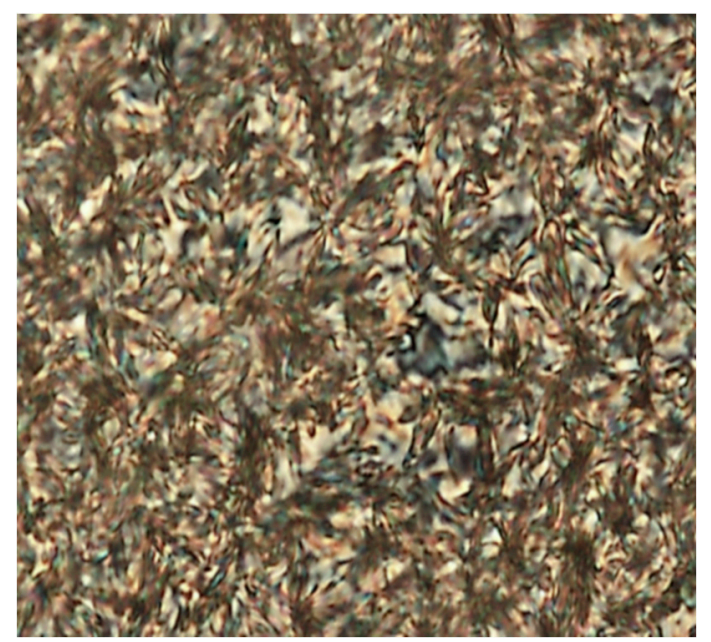

Figure 4. Optical micrograph of cured K-LCE/BN composites.

\subsection{Thermal and Mechanical Properties of K-LCE/BN Composites}

DMA can be used to investigate the viscoelastic properties and damping characteristics such as the Young's modulus (E) and the tan $\delta$, as shown in Figure 5. The storage modulus ( $\left.E^{\prime}\right)$ and loss modulus ( $\left.\mathrm{E}^{\prime \prime}\right)$ were calculated from the applied stress and strain as a function of temperature or frequency. Furthermore, the $T_{g}$ was calculated from the maximum peak position of the $\tan \delta$ curve measurement. These properties reflect the molecular relaxation of the individual materials and reveal interactions among each material of the polymer composites. Figure 5 a shows the storage modulus of the neat $\mathrm{K}-\mathrm{LCE}$ and $\mathrm{K}-\mathrm{LCE} / \mathrm{BN}$ composites at a heating rate of $5{ }^{\circ} \mathrm{C} / \mathrm{min}$; the tan delta curves of the neat K-LCE and its composites filled with different h-BN filler content are shown in Figure $5 \mathrm{~b}$. The values of the pertinent parameters are summarized in Table 1 . The storage modulus and $\mathrm{T}_{\mathrm{g}}$ of the $\mathrm{K}-\mathrm{LCE} / \mathrm{BN}$ composites (above $2460 \mathrm{MPa}, 245^{\circ} \mathrm{C}$ ) were higher than that of neat $\mathrm{K}-\mathrm{LCE}$ $\left(1968 \mathrm{MPa}, 228^{\circ} \mathrm{C}\right)$, which indicates that the mechanical properties enhancement can be attributed to the formation of covalent bridge bonding between the LC resin and functionalized h-BN fillers. Thus, silane-coupling agent played an important role in interaction and compatibility between filler and epoxy resin matrix. Nevertheless, the storage modulus and $\mathrm{T}_{\mathrm{g}}$ of the $5.00 \mathrm{wt} \%$ modified $\mathrm{BN}$-filled composites did not increased significantly compared to those of the loading of $2.00 \mathrm{wt} \%$ modified BN fillers. This result is due to the presence of some aggregations on the vitrification stage of curing reaction cause the phenomenon.

TMA is a useful technique to measure the dimensional changes of a material as a function of temperature under non-oscillating stress. TMA also is a very sensitive tool which can calculate the $\mathrm{T}_{\mathrm{g}}$ and the CTEs in both the glassy and rubbery regions. TMA thermographs of the neat K-LCE and K-LCE/BN composites are shown in Figure 6. The CTE values of the composites were gradually decreased with increasing h-BN fillers, as listed in Table 1. This is ascribed to the surface modification with silane-coupling agent APTES, which can improve the dispersion of Si-BN in the K-LCE matrix and enhance the crosslinking density of the composites, resulting in the reduction of thermal expansion. 

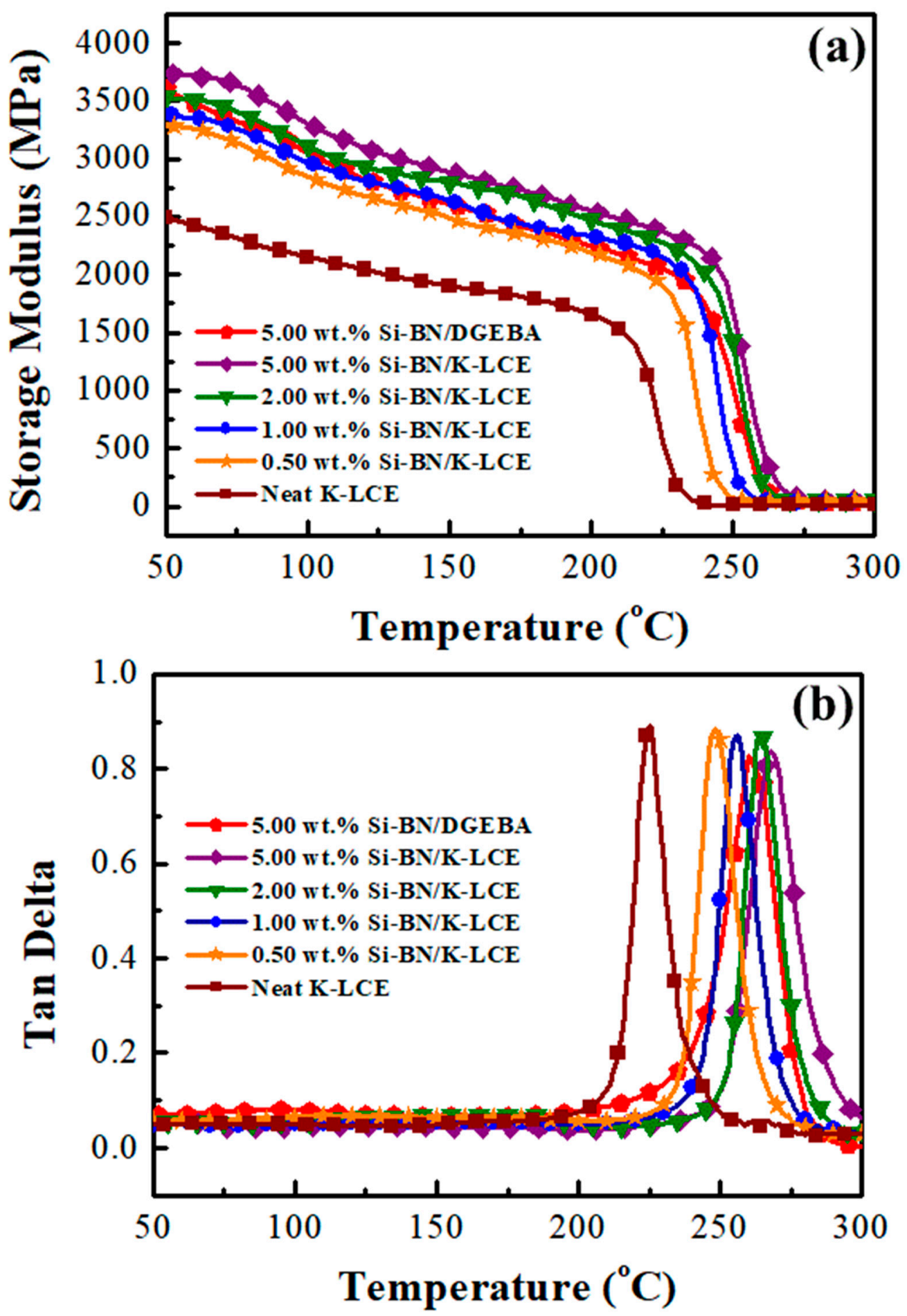

Figure 5. DMA curves of neat K-LCE and K-LCE/BN composites (a) storage modulus (b) tan delta. 


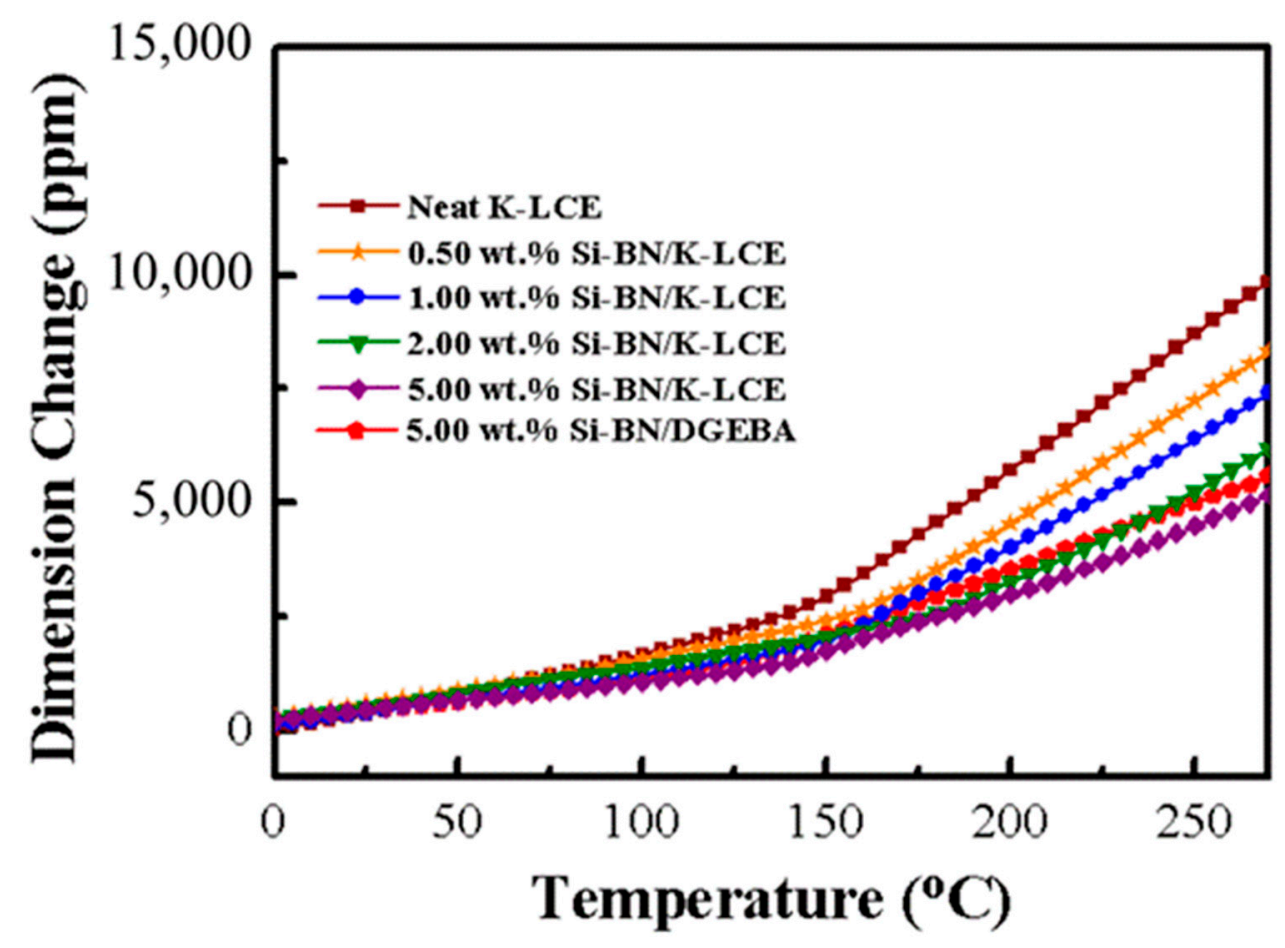

Figure 6. TMA thermographs of neat K-LCE and K-LCE/BN composites.

Table 1. Thermomechanical properties of K-LCE/BN composites.

\begin{tabular}{|c|c|c|c|c|c|c|}
\hline \multirow{2}{*}{$\begin{array}{c}\text { wt } \% \text { of } \\
\text { Si-BN }\end{array}$} & \multicolumn{3}{|c|}{$\begin{array}{c}\mathrm{E}^{\prime \mathrm{a}} \\
(\mathrm{MPa})\end{array}$} & \multirow{2}{*}{$\begin{array}{l}\mathrm{T}_{\mathrm{g}}{ }^{\mathrm{b}} \\
\left({ }^{\circ} \mathrm{C}\right)\end{array}$} & \multicolumn{2}{|c|}{$\begin{array}{c}\mathrm{CTE}^{\mathrm{c}} \\
\left(\mathrm{ppm} /{ }^{\circ} \mathrm{C}\right)\end{array}$} \\
\hline & $\mathrm{E}_{50}^{\prime}{ }^{\circ} \mathrm{C}$ & $\mathrm{E}^{\prime}{ }_{150}^{\circ} \mathrm{C}$ & $\mathrm{E}_{295^{\circ} \mathrm{C}}$ & & $\begin{array}{l}\text { Glassy } \\
\text { Region }\end{array}$ & $\begin{array}{c}\text { Rubbery } \\
\text { Region }\end{array}$ \\
\hline 0.00 & 2493 & 1968 & 124 & 228 & 70 & 157 \\
\hline 0.50 & 3279 & 2464 & 157 & 249 & 63 & 143 \\
\hline 1.00 & 3356 & 2577 & 166 & 256 & 60 & 136 \\
\hline 2.00 & 3524 & 2795 & 189 & 267 & 56 & 122 \\
\hline 5.00 & 3698 & 2812 & 193 & 271 & 53 & 117 \\
\hline
\end{tabular}

a Storage modulus measured by DMA. ${ }^{\mathrm{b}}$ Peak temperature of $\tan \delta$ curve. ${ }^{\mathrm{c}}$ Coefficient of thermal expansion measured by TMA.

The impact tester was used to study the mechanical properties of composites. The composites toughness in terms of the impact strength in the unit of $\mathrm{kJ} / \mathrm{m}^{2}$ was determined by the absorbed energy while breaking a sample under an impact load. Figure 7 shows the impact strength of the neat K-LCE and $\mathrm{K}-\mathrm{LCE} / \mathrm{BN}$ composites. It can be seen that the impact strength slightly increased with increasing $\mathrm{Si}-\mathrm{BN}$ content compared to the neat K-LCE. This indicates that the incorporation of modified BN fillers did not affect the mechanical properties of the epoxy molding compounds.

TGA was performed to further investigate the thermal stability of composites such as weight loss, decomposition temperature and char yields. The thermal stability of the neat K-LCE and its composites filled with different h-BN filler content were determined by TGA at a heating rate of $10^{\circ} \mathrm{C} / \mathrm{min}$ under nitrogen gas, as shown in Figure 8. The neat K-LCE and all composites exhibited similar decomposition temperature at $5 \%$ and $10 \%$ weight loss, respectively. This is due to the existence of rigid rod group of LC epoxy, which can resist to thermal attack. Notice that the decomposition temperature of $5.00 \mathrm{wt} \%$ modified BN-filled composites at 10\% weight loss was slightly lower compared to that of $2.00 \mathrm{wt} \%$ modified BN-filled composites. This result is may attributed to the existence of some aggregations effect the crosslinking density of composites. In addition, the char yields of the composites at $800{ }^{\circ} \mathrm{C}$ were gradually increased with increasing Si-BN fillers, as listed in Table 2. This result can be explained 
that the h-BN fillers as mass transfer barriers can form isolation layers [30]. Based on the above results, the thermomechanical properties of the composites are indeed enhanced by the incorporation of modified BN fillers.

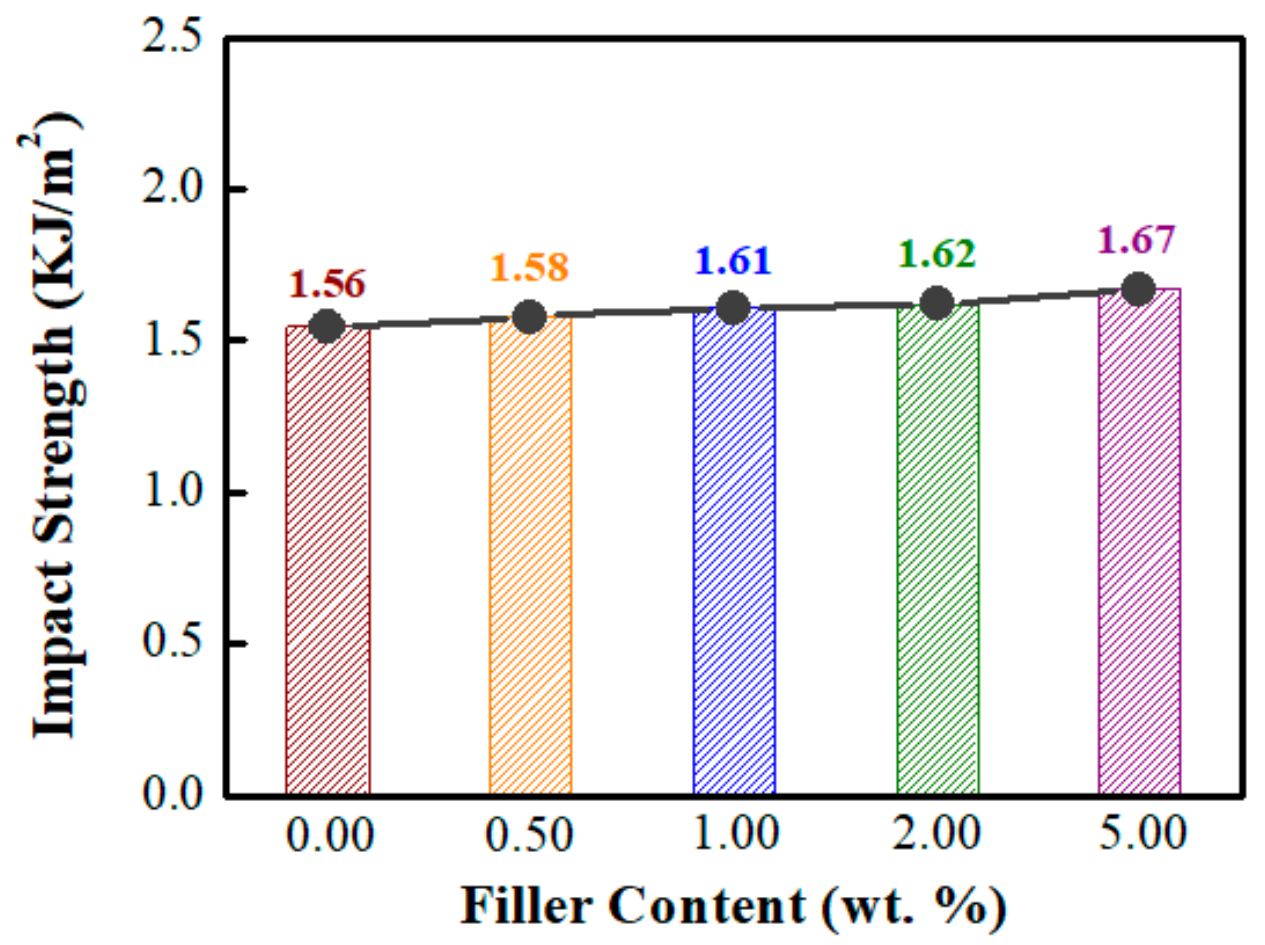

Figure 7. Impact strength of neat K-LCE and its composites filled with different Si-BN contents.

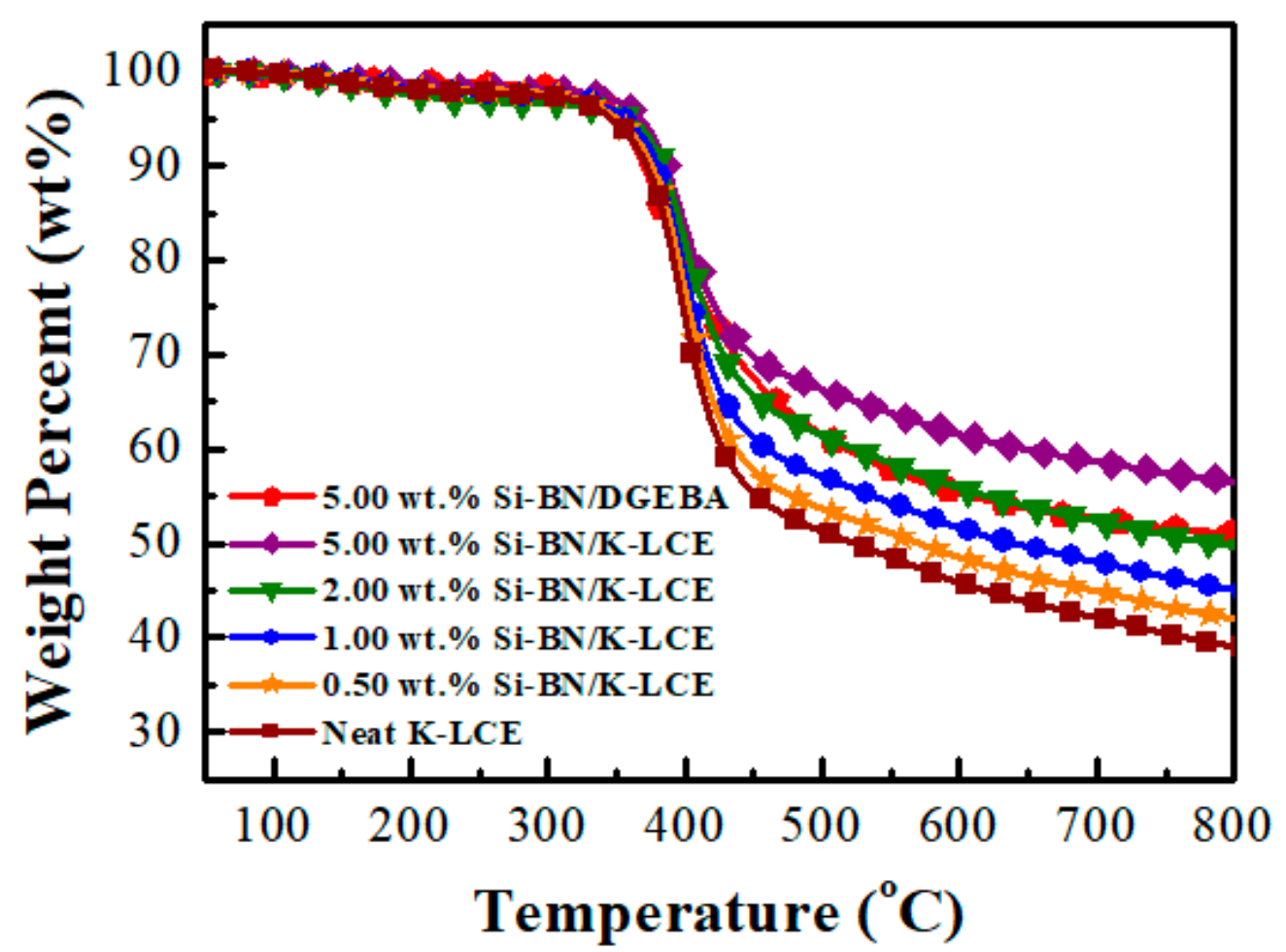

Figure 8. TGA thermograms of neat K-LCE and K-LCE/BN composites. 
Table 2. Thermal stabilities of K-LCE/BN composites.

\begin{tabular}{|c|c|c|c|}
\hline $\begin{array}{l}\text { wt } \% \text { of } \\
\text { Si-BN }\end{array}$ & $\begin{array}{c}\mathrm{T}_{\mathrm{d} 5 \%}{ }^{\mathrm{a}} \\
\left({ }^{\circ} \mathrm{C}\right)\end{array}$ & $\begin{array}{c}\mathrm{T}_{\mathrm{d} \mathrm{10} \%}{ }^{\mathrm{b}} \\
\left({ }^{\circ} \mathrm{C}\right)\end{array}$ & $\begin{array}{c}\text { Char Yield (\%) } \\
\text { at } 800{ }^{\circ} \mathrm{C}\end{array}$ \\
\hline 0.00 & 344 & 372 & 40.1 \\
\hline 0.50 & 349 & 376 & 42.9 \\
\hline 1.00 & 355 & 379 & 45.3 \\
\hline 2.00 & 363 & 384 & 49.7 \\
\hline 5.00 & 362 & 382 & 56.6 \\
\hline
\end{tabular}

${ }^{\mathrm{a}}$ Temperature for decomposition of $5 \%$ weight loss. ${ }^{\mathrm{b}}$ Temperature for decomposition of $10 \%$ weight loss.

\subsection{Thermal Conductivity of K-LCE/BN Composites}

The thermal conductivities of the neat K-LCE and K-LCE/BN composites increased along with the BN filler contents, as shown in Figure 9. The thermal conductivity values of K-LCE/BN composites with $0 \%, 0.05 \%, 1.00 \%, 2.00 \%$, and $5.00 \mathrm{wt} \% \mathrm{BN}$ filler contents were $0.34,0.39,0.45,0.53$ and $0.58 \mathrm{~W} / \mathrm{m} \cdot \mathrm{K}$, respectively. With incorporation of Si-BN to neat K-LCE, the thermal conductivity increased by $70.58 \%$ (from 0.34 to 0.58 ) at $5.00 \mathrm{wt} \% \mathrm{Si}-\mathrm{BN}$ fillers content. The enhancement in the thermal conductivity can be explained that the silane-coupling agent APTES modification improved the compatibility of h-BN fillers, which can provide the better dispersion state of $\mathrm{Si}-\mathrm{BN}$ in the K-LCE matrix, thus obtaining the good path of heat dissipation.

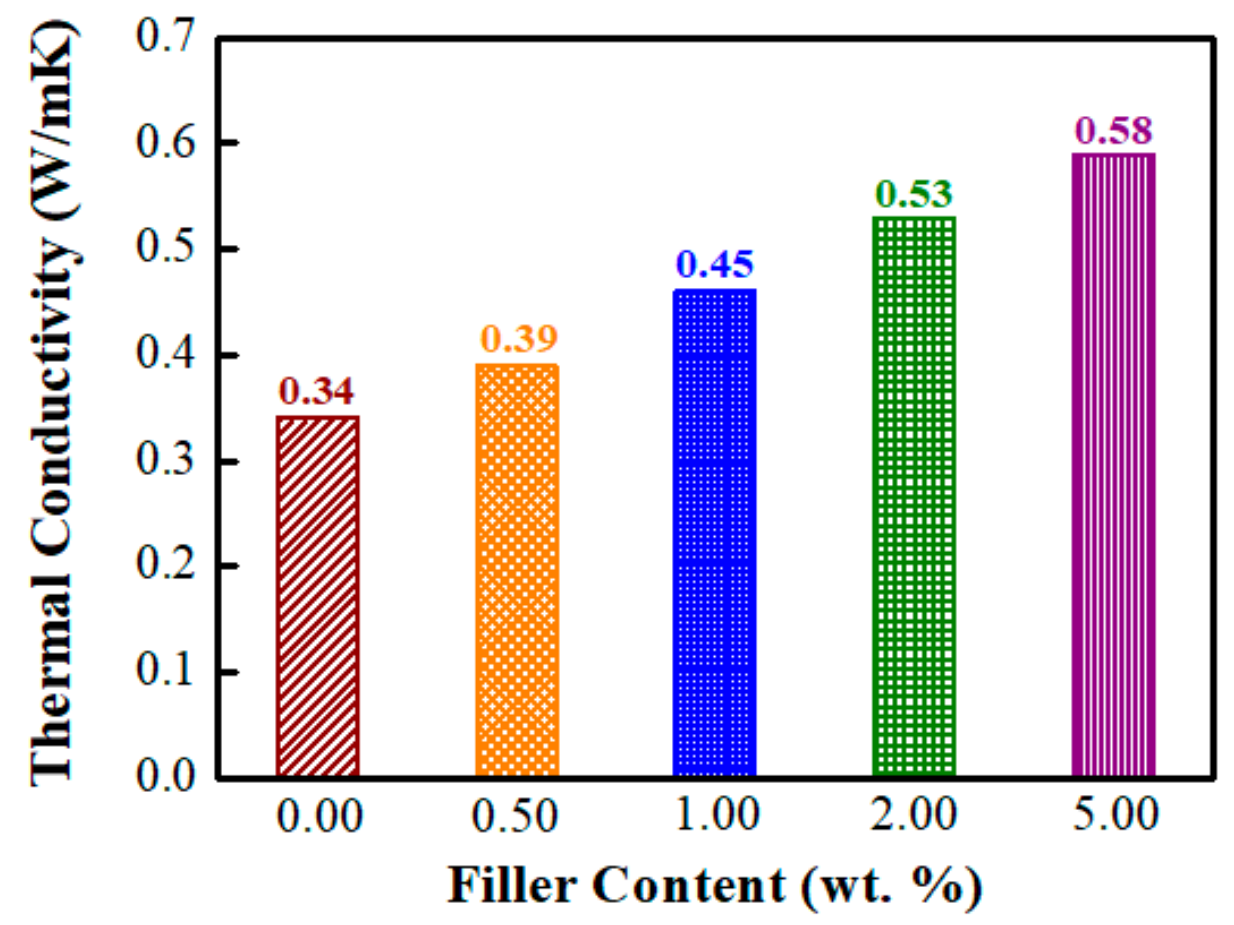

Figure 9. Thermal conductivity of neat K-LCE and its composites filled with different Si-BN contents.

In addition, the thermal and mechanical properties of the cured conventional epoxy resin (Diglycidyl ether of bisphenol A, DGEBA) composites were also investigated. The K-LCE/BN composites exhibited superior thermal and mechanical properties than DGEBA/BN composites, as summarized in Table 3. The properties of composites can be greatly enhanced when the rigid rod mesogenic structures with LC behavior are introduced, which can form a highly crosslinked composites with orderly arrangement structure. 
Table 3. Comparison of thermal and mechanical properties of K-LCE/BN and DGEBA/BN composites.

\begin{tabular}{|c|c|c|c|c|c|c|c|}
\hline \multirow{2}{*}{$\begin{array}{l}5.00 w t \% \\
\text { of } \mathrm{Si}-\mathrm{BN}\end{array}$} & \multirow{2}{*}{$\begin{array}{c}\begin{array}{c}\mathrm{E}^{\prime} \\
(\mathrm{MPa})\end{array} \\
\mathrm{E}^{\prime}{ }_{150}^{\circ} \mathrm{C}\end{array}$} & \multirow{2}{*}{$\underset{\left({ }^{\circ} \mathrm{C}\right)}{\mathrm{T}_{\mathrm{g}}}$} & \multicolumn{2}{|c|}{$\begin{array}{c}\mathrm{CTE} \\
\left(\mathrm{ppm} /{ }^{\circ} \mathrm{C}\right)\end{array}$} & \multirow{2}{*}{$\begin{array}{c}\mathrm{T}_{\mathrm{d} 10 \%} \\
\left({ }^{\circ} \mathrm{C}\right)\end{array}$} & \multirow{2}{*}{$\begin{array}{c}\text { Char Yield } \\
\text { at } 800{ }^{\circ} \mathrm{C} \\
(\%)\end{array}$} & \multirow{2}{*}{$\begin{array}{c}\text { Thermal } \\
\text { Conductivity } \\
(\mathrm{W} / \mathrm{m} \cdot \mathrm{K})\end{array}$} \\
\hline & & & $\begin{array}{l}\text { Glassy } \\
\text { Region }\end{array}$ & $\begin{array}{l}\text { Rubbery } \\
\text { Region }\end{array}$ & & & \\
\hline $\mathrm{K}-\mathrm{LCE} / \mathrm{BN}$ & 2812 & 271 & 53 & 117 & 382 & 56.6 & 0.58 \\
\hline DGEBA/BN & 2588 & 262 & 55 & 121 & 369 & 51.1 & 0.46 \\
\hline
\end{tabular}

\section{Conclusions}

$\mathrm{K}-\mathrm{LCE} / \mathrm{BN}$ composites were successfully prepared from functionalized h-BN fillers embedded in an LC epoxy resin. The silane-coupling agent APTES was used to modify raw h-BN and acted as a bridge between h-BN fillers and K-LCE matrix. The FTIR spectrum of modified h-BN confirms that APTES is successfully grafted on the surface of $\mathrm{h}$-BN fillers. The thermomechanical properties of the composites are indeed enhanced by the incorporation of modified BN fillers, and the LC epoxy/BN composites shows excellent physical properties compared to those of the traditional epoxy/BN composites. Therefore, The $\mathrm{K}-\mathrm{LCE} / \mathrm{BN}$ composite have the potential for use as a high-performance epoxy molding compounds in electronics encapsulation industry with a low CTE, high storage modulus and thermal conductivity.

Author Contributions: Conceptualization, Y.-S.L. and S.L.-C.H.; methodology, Y.-S.L. and S.L.-C.H.; formal analysis, Y.-S.L. and Y.-H.H.; investigation, Y.-S.L.; resources, T.-H.H. and L.-C.J.; data curation, Y.-S.L.; writing - original draft preparation, Y.-S.L.; writing—review and editing, S.L.-C.H., T.-H.H. and L.-C.J.; visualization, Y.-S.L. and S.L.-C.H.; project administration, S.L.-C.H. All authors have read and agreed to the published version of the manuscript.

Funding: The financial support provided by the Ministry of Science and Technology (Taiwan, R.O.C.) through project MOST 103-2120-M-006-004-CC1 is greatly appreciated.

Conflicts of Interest: The authors declare no conflict of interest.

\section{References}

1. McGlen, R.J.; Jachuck, R. Integrated thermal management techniques for high power electronic devices. Appl. Therm. Eng. 2004, 24, 1143-1156. [CrossRef]

2. Garimella, S.V.; Fleischer, A.S.; Murthy, J.Y.; Keshavarzi, A.; Prasher, R.; Patel, C.; Bhavnani, S.H.; Venkatasubramanian, R.; Mahajan, R.; Joshi, Y.; et al. Thermal Challenges in Next-Generation Electronic Systems. IEEE Trans. Compon. Packag. Technol. 2008, 31, 801-815. [CrossRef]

3. Liang, Y.C.; Zhang, J.N.; Li, M.; Guo, Y.P.; Yuan, J.S. Thermal Analysis of the Heat Exchanger for Power Electronic Device with Higher Power Density. Prz. Elektrotechniczn 2012, 88, 328-332.

4. Gonon, P.; Sylvestre, A.; Teysseyre, J.; Prior, C. Dielectric properties of epoxy/silica composites used for microlectronic packaging, and their dependence on post-curing. J. Mater. Sci. Mater. Electron. 2001, 12, 81-86. [CrossRef]

5. Harada, M.; Okamoto, N.; Kannan, P.; Ochi, M. Fracture toughness and fracture mechanism of liquid-crystalline epoxy resins with different polydomain structures. J. Polym. Sci. Part B Polym. Phys. 2010, 48, 2337-2345. [CrossRef]

6. Liu, Y.L.; Cai, Z.Q.; Wen, X.; Pi, P.; Zheng, D.; Cheng, J.; Yang, Z. A new and efficient synthetic method of a liquid crystalline epoxy resin with biphenol and aromatic ester group. Polym. Bull. 2011,67, 57-66. [CrossRef]

7. Harada, M.; Ando, J.; Ochi, M. Synthesis, Characterization, and Mechanical Properties of a Novel Terphenyl Liquid Crystalline Epoxy Resin. J. Appl. Polym. Sci. 2015, 132, 41296. [CrossRef]

8. Nazarenko, V.; Kurik, M.V.; Klimusheva, G.V.; Gotra, Z.Y.; Sorokin, V.M.; Lisetski, L.M. Liquid crystals in Ukraine and Ukrainians in liquid crystals. J. Mol. Liq. 2018, 267, 29-33. [CrossRef]

9. Lin, Y.S.; Hsu, S.L.C.; Ho, T.H.; Cheng, S.S.; Hsiao, Y.H. Synthesis, characterization, and thermomechanical properties of liquid crystalline epoxy resin containing ketone mesogen. Polym. Eng. Sci. 2017, 57, 424-431. [CrossRef] 
10. Huang, X.; Jiang, P.; Tanaka, T. A review of dielectric polymer composites with high thermal conductivity. IEEE Electr. Insul. Mag. 2011, 27, 8-16. [CrossRef]

11. Fu, J.F.; Shi, L.Y.; Zhong, Q.D.; Chen, Y.; Chen, L.Y. Thermally conductive and electrically insulative nanocomposites based on hyperbranched epoxy and nano- $\mathrm{Al}_{2} \mathrm{O}_{3}$ particles modified epoxy resin. Polym. Adv. Technol. 2011, 22, 1032-1041. [CrossRef]

12. Fang, L.; Wu, C.; Qian, R.; Xie, L.; Yang, K.; Jiang, P. Nano-micro structure of functionalized boron nitride and aluminum oxide for epoxy composites with enhanced thermal conductivity and breakdown strength. RSC Adv. 2014, 40, 21010-21017. [CrossRef]

13. Yu, Z.; Di, H.; Ma, Y.; Lv, L.; Pan, Y.; Zhang, C.; He, Y. Fabrication of graphene oxide-alumina hybrids to reinforce the anti-corrosion performance of composite epoxy coatings. Appl. Surf. Sci. 2015, 351, 986-996. [CrossRef]

14. Akhtar, M.W.; Lee, Y.S.; Yoo, D.J.; Kim, J.S. Alumina-graphene hybrid filled epoxy composite: Quantitative validation and enhanced thermal conductivity. Compos. Part B Eng. 2017, 131, 184-195. [CrossRef]

15. Lazouziet, G.; Vuksanović, M.M.; Tomić, N.Z.; Mitrić, M.; Petrović, M.; Radojević, V.; Heinemann, R.J. Optimized preparation of alumina based fillers for tuning composite properties. Ceram. Int. 2018, 44, 7442-7449. [CrossRef]

16. Choi, J.; Yang, S.; Yu, S.; Shin, H.; Cho, M. Method of scale bridging for thermoelasticity of cross-linked epoxy/SiC nanocomposites at a wide range of temperatures. Polymer 2012, 53, 5178-5189. [CrossRef]

17. Abenojar, J.; Pantoja, M.; Martinez, M.A.; Real, J.C. Aging by moisture and/or temperature of epoxy/SiC composites: Thermal and mechanical properties. J. Compos. Mater. 2015, 49, 2963-2975. [CrossRef]

18. Shen, D.; Zhan, Z.; Liu, Z.; Cao, Y.; Zhou, L.; Liu, Y.; Dai, W.; Nishimura, K.; Li, C.; Lin, C.T.; et al. Enhanced thermal conductivity of epoxy composites filled with silicon carbide nanowires. Sci. Rep. 2017, 7, 2606. [CrossRef]

19. Shi, Z.; Fu, R.; Agathopoulos, S.; Gu, X.; Zhao, W. Thermal conductivity and fire resistance of epoxy molding compounds filled with $\mathrm{Si}_{3} \mathrm{~N}_{4}$ and $\mathrm{Al}(\mathrm{OH})_{3}$. Mater. Design. 2012, 34, 820-824. [CrossRef]

20. Kusunose, T.; Yagi, T.; Fiorz, S.H.; Sekino, T. Fabrication of epoxy/silicon nitridenanowire composites and evaluation of their thermal conductivity. J. Mater. Chem. A 2013, 1, 3440-3445. [CrossRef]

21. Shimamura, A.; Hotta, Y.; Hyuga, H.; Kondo, N.; Hirao, K. Effect of amounts and types of silicon nitride on thermal conductivity of $\mathrm{Si}_{3} \mathrm{~N}_{4}$ /epoxy resin composite. J. Ceram. Soc. Jpn. 2015, 123, 908-912. [CrossRef]

22. Teng, C.C.; Ma, C.C.M.; Chiou, K.C.; Lee, T.M. Synergetic effect of thermal conductive properties of epoxy composites containing functionalized multi-walled carbon nanotubes and aluminum nitride. Compos. Part $B$ Eng. 2012, 43, 265-271. [CrossRef]

23. Choudhury, M.; Mohanty, S.; Nayak, S.K. Effect of surface modification of aluminum nitride on electrical and thermal characterizations of thermosetting polymeric nanocomposites. Polym. Compos. 2013, 34, 1-14. [CrossRef]

24. Qian, R.; Yu, J.; Xie, L.; Li, Y.; Jiang, P. Efficient thermal properties enhancement to hyperbranched aromatic polyamide grafted aluminum nitride in epoxy composites. Polym. Adv. Technol. 2013, 24, 348-356. [CrossRef]

25. He, Z.; Dai, W.; Yu, J.; Pan, L.; Xiao, X.; Lu, S.; Jiang, N. Enhanced thermal and mechanical properties of polyimide composites by mixing thermotropic liquid crystalline epoxy grafted aluminum nitride. J. Polym. Res. 2014, 21, 595. [CrossRef]

26. Wang, Y.; Qiao, X.; Wan, J.; Xiao, Y.; Fan, X. Preparation of AlN microspheres/UHMWPE composites for insulating thermal conductors. RSC Adv. 2016, 6, 80262-80267. [CrossRef]

27. Yu, J.; Huang, X.; Wu, C.; Wu, X.; Wang, G.; Jiang, P. Interfacial modification of boron nitride nanoplatelets for epoxy composites with improved thermal properties. Polymer 2012, 53, 471-480. [CrossRef]

28. Harada, M.; Hamaura, N.; Ochi, M.; Agari, Y. Thermal conductivity of liquid crystalline epoxy/BN filler composites having ordered network structure. Compos. Part B Eng. 2013, 55, 306-313. [CrossRef]

29. Hou, J.; Li, G.; Yang, N.; Qin, L.; Grami, M.E.; Zhang, Q.; Wang, N.; Qu, X. Preparation and characterization of surface modified boron nitride epoxy composites with enhanced thermal conductivity. RSC Adv. 2014, 4, 44282-44290. [CrossRef]

30. Yang, N.; Xu, C.; Hou, J.; Yao, Y.; Zhang, Q.; Grami, M.E.; He, L.; Wanga, N.; Qu, X. Preparation and properties of thermally conductive polyimide/boron nitride composites. RSC Adv. 2016, 6, 18279-18287. [CrossRef] 
31. Wu, K.; Lei, C.; Yang, W.; Chai, S.; Chen, F.; Fu, Q. Surface modification of boron nitride by reduced graphene oxide for preparation of dielectric material with enhanced dielectric constant and well-suppressed dielectric loss. Compos. Sci. Technol. 2016, 134, 191-200. [CrossRef]

32. Mittal, G.; Rhee, K.Y.; Park, S.J. Processing and characterization of PMMA/PI composites reinforced with surface functionalized hexagonal boron nitride. Appl. Surf. Sci. 2017, 415, 49-54. [CrossRef]

33. Im, H.; Kim, J. The effect of $\mathrm{Al}_{2} \mathrm{O}_{3}$ doped multi-walled carbon nanotubes on the thermal conductivity of $\mathrm{Al}_{2} \mathrm{O}_{3}$ /epoxy terminated poly(dimethylsiloxane) composites. Carbon 2011, 49, 3503-3511. [CrossRef]

34. Hsu, S.; Wu, M.C.; Chen, S.; Chuang, C.M.; Lin, S.H.; Su, W.F. Synthesis, morphology and physical properties of multi-walled carbon nanotube/biphenyl liquid crystalline epoxy composites. Carbon 2012, 50, 896-905. [CrossRef]

35. Ma, A.; Chen, W.; Hou, Y. Mechanical and Thermal Conductivities of MWCNTs/Si $3 \mathrm{~N}_{4} / \mathrm{Epoxy}_{\text {Composites. }}$ Polym. Plast. Technol. Eng. 2013, 52, 1590-1594. [CrossRef]

36. Hsiao, M.C.; Ma, C.C.M.; Chiang, J.C.; Ho, K.K.; Chou, T.Y.; Xie, X.; Tsai, C.H.; Changa, L.H.; Hsieh, C.K. Thermally conductive and electrically insulating epoxy nanocomposites with thermally reduced graphene oxide-silica hybrid nanosheets. Nanoscale 2013, 13, 5863-5871. [CrossRef]

37. Kausar, A.; Rafique, I.; Anwar, Z.; Muhammad, B. Perspectives of Epoxy/Graphene Oxide Composite: Significant Features and Technical Applications. Polym. Plast. Tech. Eng. 2016, 55, 704-722. [CrossRef]

38. Pourhashem, S.; Vaezi, M.R.; Rashidi, A.; Bagherzadeh, M.R. Exploring corrosion protection properties of solvent based epoxy-graphene oxide nanocomposite coatings on mild steel. Corros. Sci. 2017, 115, 78-92. [CrossRef]

(C) 2020 by the authors. Licensee MDPI, Basel, Switzerland. This article is an open access article distributed under the terms and conditions of the Creative Commons Attribution (CC BY) license (http://creativecommons.org/licenses/by/4.0/). 